\title{
Dynamic Optimization of Inner Dump in Open-Pit Mining With Irregular Boundary
}

\author{
Haoran $\mathrm{Li}^{1}$, Han $\mathrm{Du}^{2}$, Runcai Bai ${ }^{1}$, Guangwei Liu ${ }^{1}$ \\ ${ }^{1}$ Liaoning Technical University, School of Mining, LiaoNing, FuXin, China \\ ${ }^{2}$ Department of Hydraulic Engineering, State Key Laboratory of Hydroscience and Engineering, \\ Tsinghua University, Beijing, China \\ *Corresponding Author.
}

\begin{abstract}
In order to maximize the profit of open-pit mining with irregular boundary, a dynamic optimization method of internal drainage field is proposed according to the open-pit mining principle. The method according to the site within the space and the relationship between the volume of debris, there will be no rules state within the cross mining row of open pit mining engineering is divided into three periods, namely: site within the space of stage saturated site, inner space, site in excess phase space; By building the stope - inside the mine production model, will work in mine stope and line contact with the three periods established relationship, analyses the various periods stripping engineering problems, and puts forward the corresponding solutions, and for optimal solution. This method is applied to the henan open-pit mine of hollin, a state power investment group. In another mining period, the internal drainage space is fully utilized, which reduces the area of land expropriation by the external drainage and achieves the purpose of reducing cost and increasing efficiency.
\end{abstract}

Keywords: Keyword one, keyword two, keyword three, keyword four, keyword five

\section{Introduction}

The development and construction of the inner dump is an important production link the open-pit mines. There are many factors that restrict the development and construction of inner dumps in open-pit mines, such as the base form and bearing capacity of inner dumps, open-pit mine engineering, coal bed storage conditions, etc. [1-5] However, most of the previous studies failed to focus on the influence of the mining boundary of open-pit mines on the development and construction of the inner dumps in open-pit mines.

The traditional method is used to delineate the boundary of open-pit mines. The coal bed is usually regarded as a whole, and the stripping ratio of the open-pit mine boundary is determined by using the sidewall line ratio method. Based on the principle that the boundary stripping ratio is less than and equal to the economic (reasonable) stripping ratio [6], the mining boundary of the open-pit mine is delineated. However, the limitations of geological conditions make the mining boundary of many open-pit mines rather irregular, that is, the mining boundary of open-pit mines cannot guarantee that the working line of open-pit mines can be kept within a stable range in the implementation As a result, the production process cannot be orderly carried out. For example, in the process of delineating the boundary, when the delineated range is a valley with great hypsography, the final boundary will be irregular although the coal bed storage is relatively stable (Heidaigou open-pit mines). When the delineated range is a plain with little hypsography, the coal bed is not fully developed or the coal thickness changes greatly, which makes the final boundary irregular (Zhahanaoer open-pit mines). Because of limitations in geography or personal factors, the boundary of open-pit mines is also irregular (Huolinhe open-pit mines). Regarding the open-pit mines with irregular boundaries caused by the situations above, the volume of the stripped materials doesn't always match the volume of the inner dump in the open-pit mines. Three kinds of relationships exist between them, namely, saturated inner dump space, insufficient inner dump space and surplus inner dump space. Among them, the saturation and surplus of the inner dump space are in the unbalanced development stages of inner dump.

ISSN: 0010-8189 
Because the distance between the stope and the dump varies greatly in each period, the load distance and the dumping space of the stripped materials also change, which makes the mine production cost fluctuate greatly. Therefore, in order to maximize the mining benefits of open-pit mines that have irregular boundaries and are horizontally mined in each period, it is necessary to dynamically optimize the dumping site within its mining scope for the the purpose of reducing the cost and increasing the efficiency [7-13].

This paper was based on the development characteristics of the stripping projects after realizing the inner dumping of open-pit mines that had irregular boundaries and were horizontally mined. The mining models of open-pit mines were first established in the paper. As irregular boundaries caused the unmatched dump space and stripping amount, the paper analyzed the influence of irregular boundaries on the stripping projects in each period. Moreover, the paper not only studied the dynamic optimization of the dump in unbalanced dumping stages but also verified the results by using the open-pit mine south of Huolinhe in the open-pit coal industry.

Manuscripts must be written in English. Authors whose native language is not English are recom-mended to seek the advice of a native English speaker, if possible, before submitting their manu-scripts. The pages in the manuscript should not be numbered and in the text no reference should be made to page numbers; if necessary, one may refer to sections. Try to avoid excessive use of italics and bold face.

\section{Mining analysis of open-pit mines with irregular boundaries and horizontal mining}

\subsection{Open-pit mine modelling}

The distance between the inner dump and the stope is equal to the safe distance after the horizontal mining and the inner dump are completely realized in the typical open-pit mine [14-15]. Regarding the open-pit mines with irregular boundaries and horizontal mining, irregular boundaries caused the mismatch of the operating line length both in the stope and in the dump. As a result, it caused three conditions, namely, saturation, insufficiency and surplus in inner dump space. The open-pit mining model was established to analyze the three engineering conditions. If there are $n$ coal beds from top to bottom in an open-pit mine, the advancing directions of both the stope and the dump are the same. The technical parameters are set as follows: the annual advancing distance of the stope working line is $\mathrm{L}_{c}$, and the length of the stope working line is $\mathrm{L}_{\mathrm{m}}$. The annual advancing distance of the inner

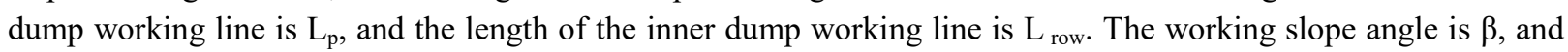
the working slope angle of the inner dump is $\alpha$. The safe distance between the stope and the dump is a. The output of the open-pit mine is $\mathrm{A}$, the stripping ratio is $\mathrm{N}$, and the looseness coefficient is $\mathrm{S}$. The final receiving height of the dump is equal to the mining depth of the stope, h, as shown in the Fig. 1.

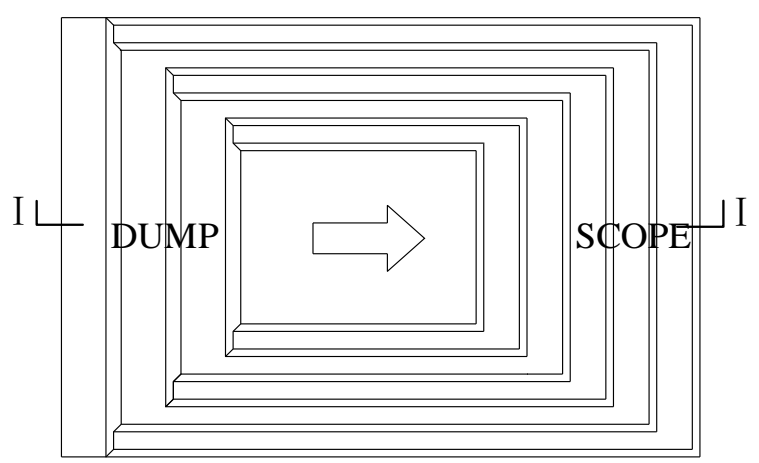

(a) Open-pit mine 


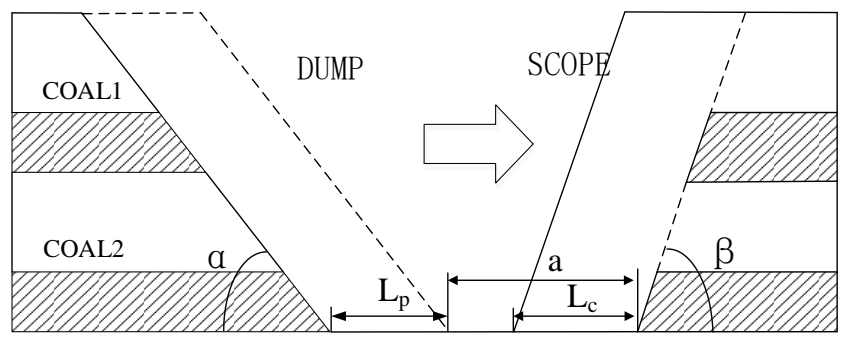

(b) I-I profile

Fig 1 Open-pit mine modelling

The tracking distance $\mathrm{d}$ between the dump and the stope can be expressed as $\mathrm{d}=L_{c}-L_{p}$. Based on the mining model of the stope and the dump, the following relationship could be obtained.

$$
\begin{aligned}
\mathrm{An}+\mathrm{A} & =L_{c} h L_{\mathrm{m}} \\
\mathrm{Ans} & =L_{p} h L_{\text {row }} \\
L_{c} & =\frac{\mathrm{An}+\mathrm{A}}{h L_{\mathrm{m}}} \\
L_{p} & =\frac{\text { Ans }}{h L_{\text {row }}}
\end{aligned}
$$

2.2 Mining analysis of open-pit mines with irregular boundaries and horizontal mining

\subsubsection{Inner dump space saturation}

During the production period, the boundary shape of open-pit mines is relatively regular, and the stripped materials are completely discharged inside. The follow-up distance between the stope and the dump is exactly the safe distance. At this time, each production link and parameters of the open-pit mine are in a relatively ideal state. Also, the advancing distance of the stope is equal to that of the inner dump, namely, if $L_{c}=L_{p}$, and then $\frac{L_{c}}{L_{p}}=$ $\frac{(n+1) L_{\text {row }}}{n s L_{m}}=1$. Thus, it can be deduced that: the relationship between the working line length of the stope and that of the dump is $\frac{L_{\mathrm{m}}}{L_{\mathrm{row}}}=\frac{n+1}{n s}$. If the stripping project in open-pit mines develops like this, the inner dump will have sufficient space to hold the stripping materials produced in the stope. The tracking distance is equal to the safe distance, that is, $\mathrm{d}=\mathrm{a}$. At this time, the internal dump load distance of the truck is the minimum. The space saturation state of the inner dump is shown in the Fig. 2.

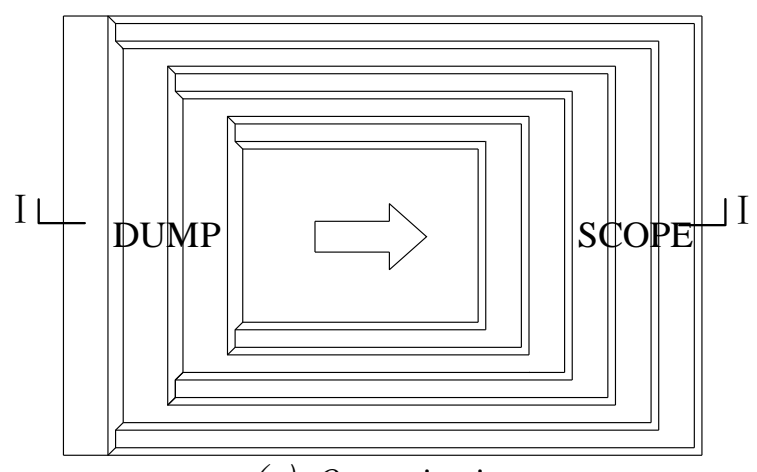

(a) Open-pit mine 


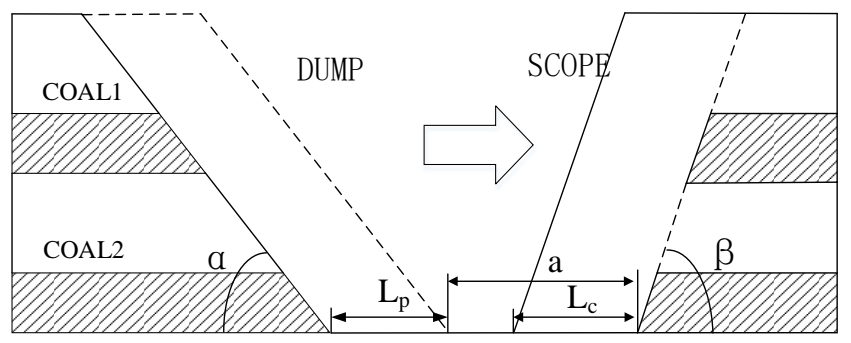

(b) I-I profile

Fig 2 Inner dump space saturation

\subsubsection{Inner dump space surplus}

When the long narrow open-pit mine is exploited within the scope of the irregular boundary, the stope working line may become shorter. In order to maintain the mine production scale, the advance degree of the stope will increase, but both the working line and the advance degree of the inner dump remain the same. As a result, the follow-up distance between the stope and the dump increases, and the load distance of the inner damp also increases. The simplified sketch map of the inner dump load distance is shown in Fig.3. The original inner dump route can be expressed as AB-BC-CD, and it later becomes AB-BC-CE-EF because of the changes in the working line length of the stope. The calculation formula of the mean load distance for the inner dump is shown in Equation 1:

$$
\mathrm{D}=D_{c}+\frac{L_{c} L_{c}^{\prime}}{K}+D_{a}(1)
$$

In the equation, $\mathrm{D}$ is the mean load distance of stripped materials in the inner dump, $\mathrm{km} ; \mathrm{L}_{c}$ is the length of the mining working line; $L_{c}^{\prime}$ is the length of the dump working line; $K$ is the coefficient. In the case of the mono-wing inner dump, $K=2$. In the case of the twin-wing inner dump, $K=4 . D_{a}$ is the appendix distance, is the horizontal load distance, namely, $\max \left(D_{1}, D_{2}\right) . D_{1}$ is the load distance obtained through the gravity center computation of the stope and dump, $D_{2}=\sqrt{\left(\frac{\Delta z}{I} \cdot C\right)^{2}+\Delta z^{2}}$ is the limiting gradient of the road, is the coefficient of the transportation development line[14-15].

Therefore, the original load distance is $L_{1}=L_{\text {row }}+L_{d}+L_{\mathrm{m}}$.

The current load distance is $L_{2}=L_{\text {row }}+L_{d}+\sqrt{\left(a L_{\mathrm{m}}\right)^{2}+\left(\Delta L_{c}\right)^{2}}$

Obviously, $L_{2}>L_{1}$. 


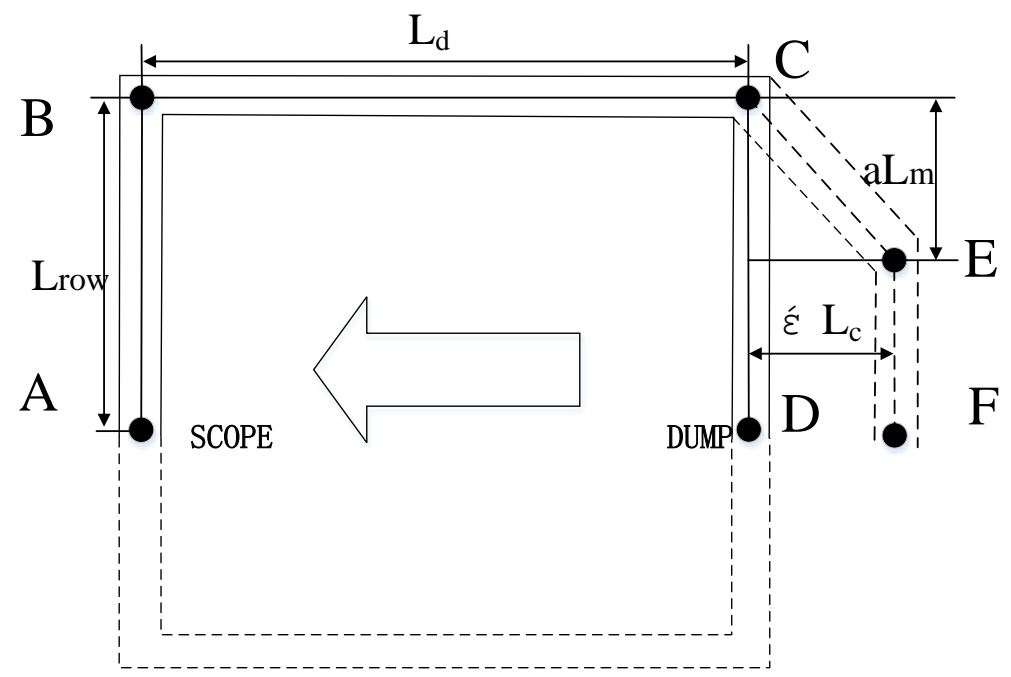

Fig 3 Analysis of the change of the internal row distance

The horizontal mining and inner dump are completely realized in open-pit mines in this production status. At this time, the advancing distance of the stope is greater than that of the inner dump, namely, if $L_{c}>L_{p}$, and then $\frac{L_{c}}{L_{p}}=\frac{(n+1) L_{\mathrm{row}}}{\mathrm{ns} L_{\mathrm{m}}}>1$. Thus, it can be deduced that the relationship of the working line length between the stope and the dump is $\frac{L_{\mathrm{m}}}{L_{\mathrm{row}}}<\frac{n+1}{n s}$. If the stripping projects in open-pit mines develop like this, the inner dump will have sufficient space to hold the stripping materials produced in the stope. The tracking distance is much greater than the safe distance, and the inner dump load distance of the truck also increases. The inner dump space surplus is shown in the Fig 4.

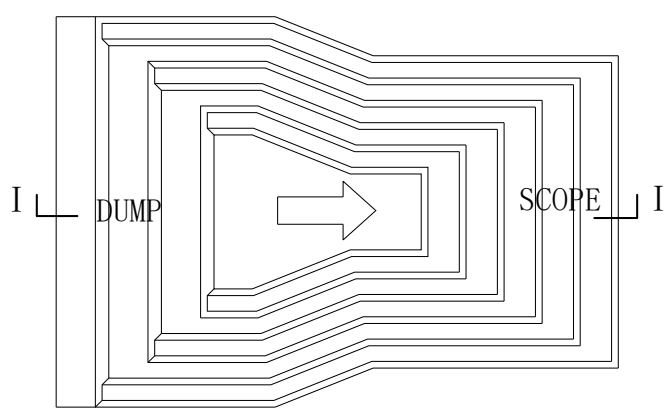

(a) Open-pit mine

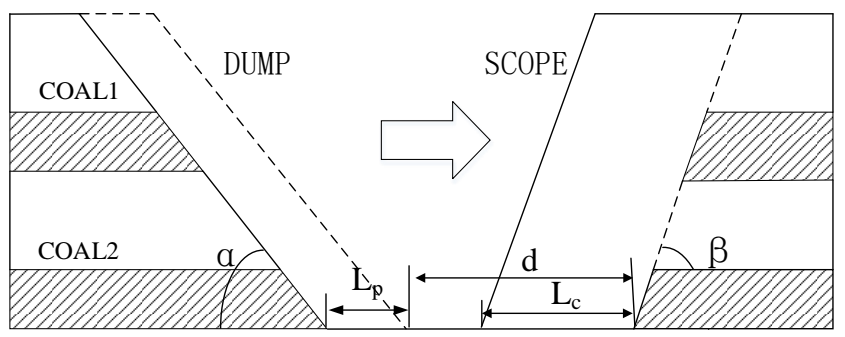

(b) I-I profile

Fig 4 Inner dump space surplus

\subsubsection{Inner dump space insufficiency}

When the open-pit mine is exploited within the scope of the irregular boundary, the stope working line may become longer. In order to maintain the mine production scale, the advance degree of the stope will drop. In addition, both the working line and the advance degree of the inner dump remain the same. As a result, the inner dump space is insufficient when the original follow-up distances remain the same in both the stope and the dump.

ISSN: 0010-8189 
In the production period, the released inner dump space is insufficient. At this time, the advance distance of the stope is less than that of the inner dump, namely, if $L_{c}<L_{p}$, and then $\frac{L_{c}}{L_{p}}=\frac{(n+1) L_{\mathrm{row}}}{\mathrm{ns} L_{m}}<1$. It can be deduced that the relationship of the working line length between the stope and the dump is $\frac{L_{\mathrm{m}}}{L_{\mathrm{row}}}>\frac{n+1}{n s}$. If the stripping projects in open-pit mines develop like this, the inner dump won't have sufficient space to hold the stripping materials produced in the stope. The tracking distance is less than the safe distance, so the inner dump parameters require certain adjustment to satisfy the dumping needs. The inner dump space insufficiency is shown in the Fig 5.

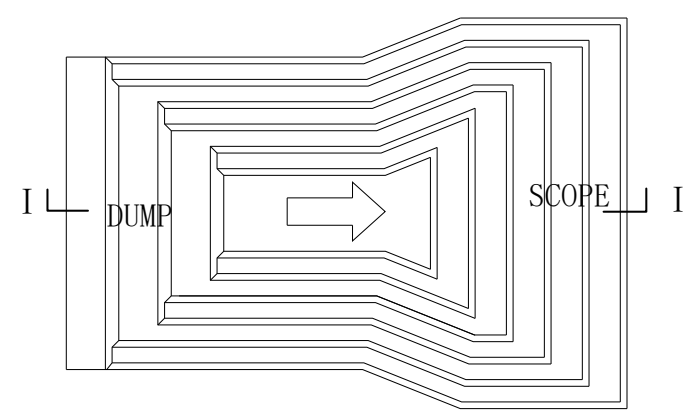

(a) Open-pit mine

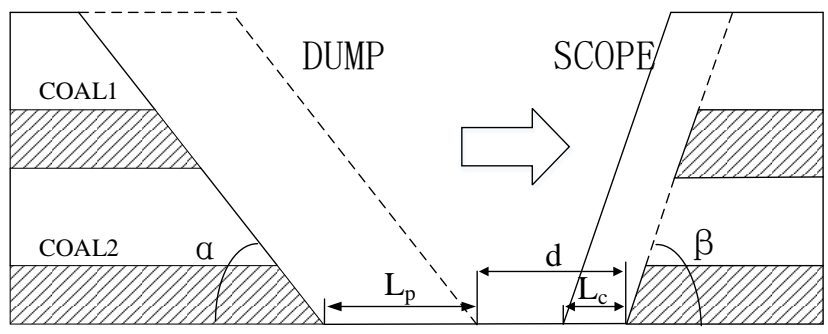

(b) I-I profile

Fig 5 Inner dump space insufficiency

\section{Optimization Method Analysis of the Inner Dump}

From the above analysis, it can be seen that: the inner dump space that is released in the insufficient stage of the inner dump fails to meet the needs of mine production when the current parameters are the same. In the surplus stage of the inner dump, the greater tracking distance causes the greater load distance. Meanwhile, the production cost also fluctuates. Aiming at the above problems, the corresponding optimization method is proposed according to the mining design principle of the open-pit mine.

3.1 Optimization analysis in the stage of the inner dump space surplus

From the analysis in section 2.2 , it can be seen that: for the limitations in the boundary shapes, when the working line length of the stope becomes shorter and the advance degree increases, the tracking distance between the inner dump and the stope increases. Therefore, the mean load distance of the inner dump increases, making the production cost higher. In order to avoid the influence of boundary shapes on the production in the stage, the dynamic adjustment should be made to the inner dump so that the tracking distance and the load distance can be shortened.

The tracking distance between the dump and the stope can be shortened by reducing the final dump elevation or the slope angle of the inner dump. The open-pit mining model was established to analyze and compare the effects of the two methods on the optimization of the load distance. Fig. 6 and 7 show the two methods to shorten the tracking distance.

In order to compare the advantages and disadvantages of two ways, namely, reducing the step height and the working slope angle of the dump, the process in which the exploited materials were transported from the stope to ISSN: 0010-8189 
the dump is equivalent to the process of the corresponding centroid motions. The coordinate system was established, where the origin is the projective point of the apex at the dump slope in the horizontal direction, the advance direction is the positive direction of $\mathrm{X}$ axis, and the direction perpendicular to $\mathrm{X}$ axis and pointing to the earth's surface is he positive direction of Y axis. Suppose the heights of both the stope and the inner dump are the same, and then the accumulated materials of the dump can be equivalent to the area of the quadrilateral $\mathrm{ABCD}$ in the model.

In the optimization of the inner dump, the dumping volume remains the same because the output and the stripping ratio don't change, namely, the area of the quadrilateral that is used to express the volume of the dump remains the same. The centroid coordinate formula of the quadrilateral is shown as follows.

$$
\mathrm{x}=\frac{\sum_{i=2}^{n-1}\left(x_{1}+x_{i}+x_{i+1}\right)\left|\begin{array}{ccc}
x_{1} & y_{1} & 1 \\
x_{i} & y_{i} & 1 \\
x_{i+1} & y_{i+1} & 1
\end{array}\right|}{3 \sum_{i=2}^{n-1}\left|\begin{array}{ccc}
x_{1} & y_{1} & 1 \\
x_{i} & y_{i} & 1 \\
x_{i+1} & y_{i+1} & 1
\end{array}\right|}
$$

3.1.1 Reduce the elevation of the inner dump only

The way of only reducing the elevation of the dump means: the follow-up distance is increased by reducing the maximum dump height when the working slope angle of the dump remains the same. As mentioned above, the dumping volume remains the same during the optimization, so the following requirement is met in the follow-up process:

\section{$S Y A B C D=S Y A^{\prime} B C D$}

$$
\begin{gathered}
(h-\Delta h) \Delta L_{p}=L_{p} \Delta h \\
\Delta L_{p}=\frac{L_{p} \Delta h}{(h-\Delta h)} \\
\Delta L_{p}=d-a
\end{gathered}
$$

As shown in the figure, the point coordinates of the quadrilateral $A^{\prime} B C D$ is as follows:
A: $(\Delta h \cot \alpha, h-\Delta h)$
B: $\left(\Delta h \cot \alpha+L_{p}+\Delta L_{p}, h-\Delta h\right)$.
C: $\left(h \cot \alpha+L_{p}+\Delta L_{p}, 0\right)$
D: $(\Delta h \cot \alpha, 0)$

According to the polygonal centroid coordinate formula, the centroid coordinates of the quadrilateral $\mathrm{A}^{\prime} \mathrm{BOD}$ are:

$$
\text { centroid coordinates } \frac{(h+\Delta h) \cot \alpha+L_{p}+\Delta L_{p}}{2}, \frac{h-\Delta h}{2}
$$




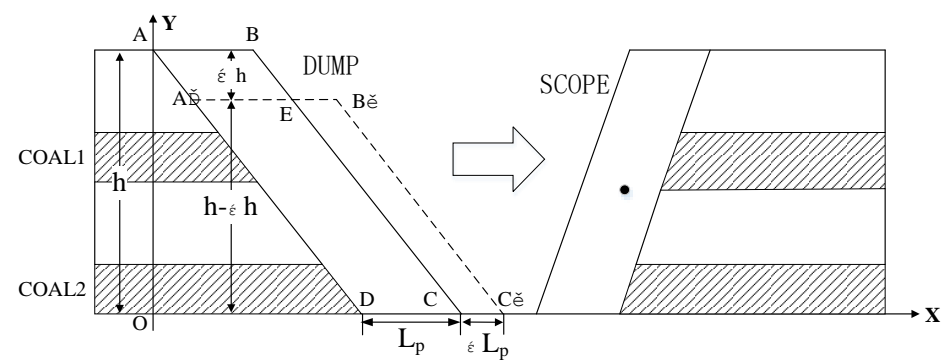

Fig 6 Optimization analysis of lowering inner drainage elevation

3.1.2 Reduce the working slope angle of the inner dump only

The way of only reducing the working slope angle of the dump means: the follow-up distance is increased by reducing the working slope angle of the dump when the maximum dump height of the inner dump remains the same. As mentioned above, the dumping volume remains the same during the optimization, so the following requirement is met in the follow-up process:

\section{$S Y A B C D=S Y A^{\prime} B C D$}

\section{$S V B E=S V D E D$}

As shown in the figure, the point coordinates of the quadrilateral $\mathrm{A}^{\prime} \mathrm{BCD}$ is as follows:
A: $(0, h)$
B: $\left(L_{p}-\Delta L_{p}, h\right)$
C: $\left(h \cot \alpha+L_{p}+\Delta L_{p}, 0\right)$
D: $(h \cot \alpha, 0)$

According to the polygonal centroid coordinate formula, the centroid coordinates of the quadrilateral $\mathrm{A}^{\prime} \mathrm{B} C \mathrm{D}$ are:

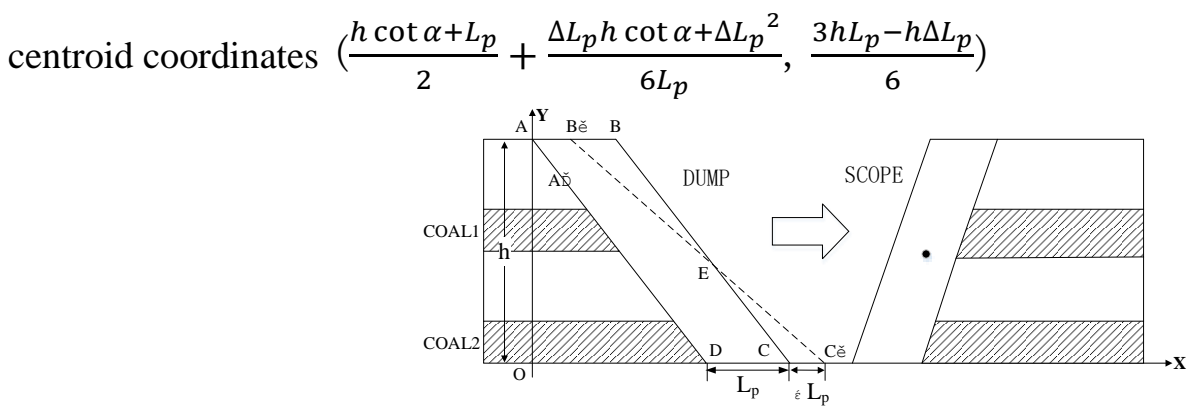

Fig 7 Analysis on reducing slope angle of inner drainage slope

The centroid trajectories of the inner dump are first obtained by only reducing the elevation and the working slope angle of the inner dump, and then the trajectories are placed in the system of rectangular coordinates to obtain the following results. 


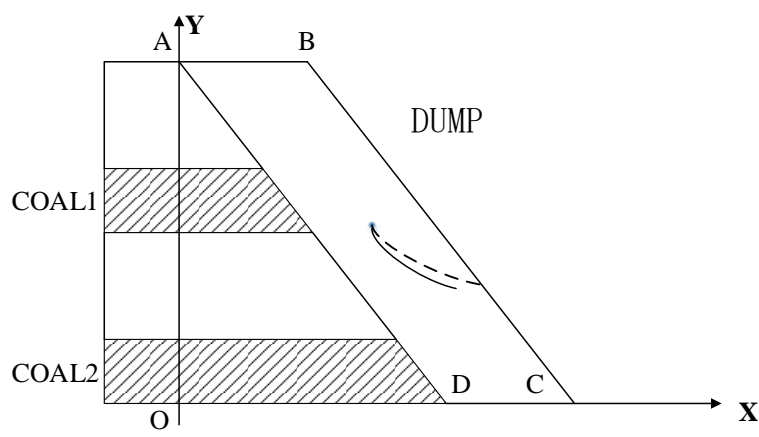

Fig 8 Comparison of optimization methods

As shown in the figure, the motion trajectories of the centroid points are dashed lines in each formed quadrilateral by only reducing the elevation. The motion trajectories of the centroid points are full lines in each formed quadrilateral by only reducing the working slope angle of the inner dump. The centroid points of the quadrilateral formed by only reducing the elevation are marked as $\left(X_{A}, Y_{A}\right)$, and those formed by only reducing the working slope angle of the inner dump are marked as $\left(X_{B}, Y_{B}\right) . X_{A}, X_{B}, Y_{A}, Y_{B}$ are processed as follows.

$$
X_{B}-X_{A}=\frac{h \cot \alpha+l_{p}}{2}+\frac{\Delta l_{p} h \cot \alpha+\Delta l_{p}^{2}}{6 l_{p}}-\frac{(h+\Delta h) \cot \alpha+l_{p}+\Delta l_{p}}{2}<0 \mathrm{c}
$$

The formula is permanently workable.

$$
Y_{A}-Y_{B}=\frac{h-\Delta h}{2}-\frac{3 h l_{p}-h \Delta l_{p}}{6}<0
$$

The formula is permanently workable.

According to the above analysis: in order to reduce the follow-up distance of the inner dump, reducing the elevation of the inner dump has obvious advantages in the same conditions. Namely, when the same distance is advanced forward, reducing the elevation of the dump can make the motion range of the inner dump centroid points towards the stope and the vertical motion range greater than the reduced working slope angle of the inner dump. This suggests that the reduction of the dump elevation causes the load distance and the hoisting height of the inner dump to decrease. Therefore, in the dynamic optimization of the inner dump in the open-pit mine with irregular boundaries, when the relationship of the working line between the stope and the inner dump is presented as $\frac{L_{\mathrm{m}}}{L_{\text {row }}}<\frac{n+1}{n s}$, the space is optimized by reducing the elevation of the inner dump.

\subsection{Optimization analysis in the stage of the inner dump space insufficiency}

From the analysis in section 1.2, it can be seen that: for the limitations in the boundary shapes, when the working line length of the stope becomes longer and the advance degree decreases, the tracking distance between the inner dump and the stope decreases. Therefore, it causes the inner dump space insufficiency and makes it difficult to dump completely. The inner dump heightening is the first choice to solve the shortage of inner dumping in open-pit mines. While ensuring the stability of the dump slope, the inner dumping space can be increased by lifting the final dumping height of the inner dump. When the inner dump heightening fails to solve the dump space insufficiency, the reverse inner dump method could be properly used, namely, the stripped materials are placed in the unused dump space or the upper part of the used dump space.

As shown in the figure, the inner dump space remains the same in the dynamic optimization of the dump, namely, $S Y B B C C=S X F B A$. The heightening value of the inner dump is Vh, and the minimum working berm width of the dump is $\mathrm{k}$. The following can be obtained based on the equation above.

$$
\frac{1}{2}[k+(k+2 \Delta h \cot \alpha)] \Delta h=\Delta L_{p} h
$$




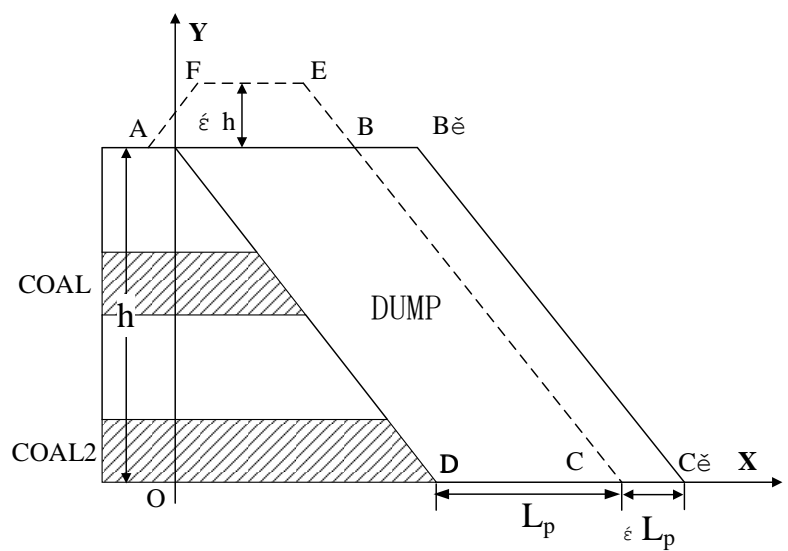

Fig 9 Schematic diagram of increased internal discharge

\subsection{Comprehensive analysis}

According to the analysis above, the unbalanced inner dump is optimized. In the case of $\frac{L_{\text {G }}}{L_{\text {国 }}}<\frac{n+1}{n s}$, the inner dump elevation is reduced for optimization. The relationship between the advance distance and the decreasing height in the dump is expressed as follows.

$$
\Delta h=\frac{h \Delta L_{p}}{\Delta L_{p}+L_{p}}
$$

In the case of $\frac{L_{\mathrm{m}}}{L_{\text {row }}}>\frac{n+1}{n s}$, it is given a priority to increase the elevation of the dump. When the inner dumping cannot be heightened further, the reverse inner dumping is used for optimization.

As shown below, the sketch map shows how the methods above are used for the dynamic optimization of the inner dump in open-pit mines with irregular boundaries.

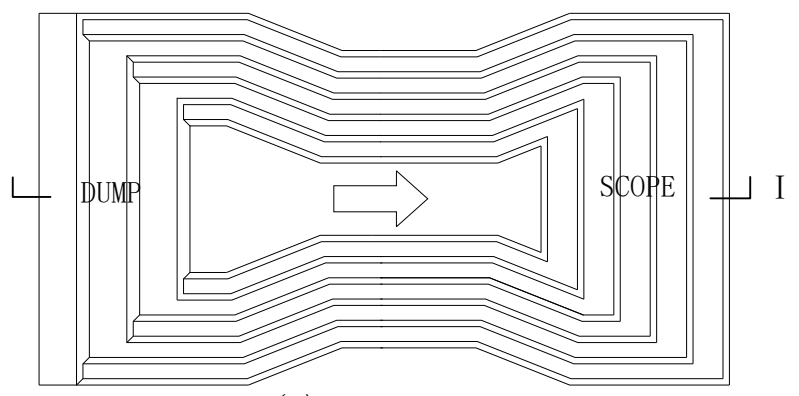

(a) Open-pit mine

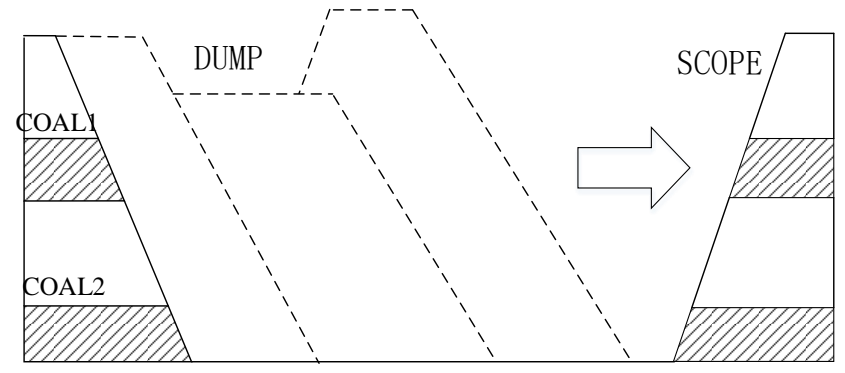

(b) I-I profile

Fig 10 Effect picture after optimization

\section{Case Study}

ISSN: 0010-8189 
The designed production capacity of Huolinhe open pit mine is $18 \mathrm{Mt} / \mathrm{a}$, the length of boundary strike is $8.05 \mathrm{~km}$, and the length of boundary changes from $1.40 \mathrm{~km}$ to $3.21 \mathrm{~km}$ in the dip direction, which is a typical irregular boundary open pit mine. There are 9 minable coal seams in Huolinhe open pit mine, which are 6, 8, 10, 11, 14, 17, 19,21 and 24 from top to bottom. The average total minable thickness is $81.17 \mathrm{~m}$, and most of them are thick and extra thick composite coal seams. Among them, 14, 17, 19 and 21 are the main minable coal seams in the open pit, with the average total minable thickness of $47.69 \mathrm{~m}$, the average unit weight of $1.27 \mathrm{t} / \mathrm{m} 3$ and the average recovery rate of $97 \%$. The south mining area of the mine has realized horizontal mining and internal drainage, and the internal drainage mode is double ring internal drainage and pressure side. The upper two steps of the internal drainage adopt the parallel operation of the dumper, and the lower part adopts the single bucket truck. The slope angle of inner drainage is $16^{\circ}$, The minimum working width of the inner dump is $60 \mathrm{~m}$, the height of the stope and the inner dump is $240 \mathrm{~m}$, the limit height of the slope is $300 \mathrm{~m}$, and the loose coefficient of the stripping material is 1.2. Due to the limitation of working conditions, Huolinhe open pit mine is short of space for external discharge. Every year, there is $15 \mathrm{mt}$ of space for external discharge of the dumper, and the rest of the stripping materials have to enter the internal discharge. 71 yuan $/ \mathrm{m}^{3} \cdot \mathrm{km}$.

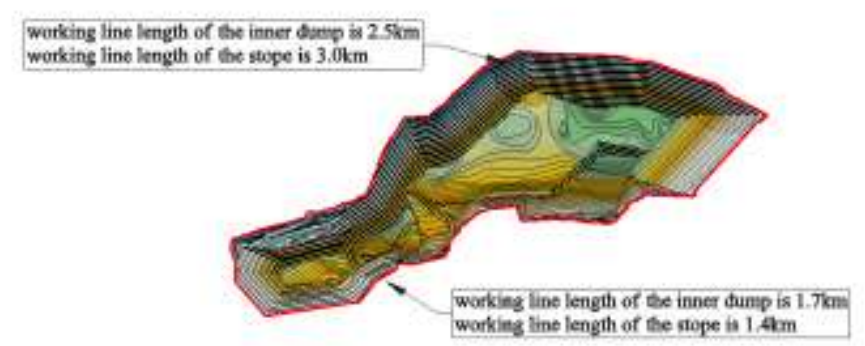

Fig 11 Huolinhe south open air boundary map

1. mined until a certain year: In the inner dump of the open-pit mine, the working line length is $1,700 \mathrm{~m}$ and the advance distance is $143 \mathrm{~m}$; the working line length of the stope is $1,400 \mathrm{~m}$, and the advance distance is $235 \mathrm{~m}$. The production stripping ratio is $3.4 \mathrm{~m} / \mathrm{t}$. It is a typical stage of the inner dump space surplus. Without optimization, the tracking distance between the inner dump and the stope is $92 \mathrm{~m}$, the load distance of the inner dump is $3.65 \mathrm{~km}$, and the total cost of truck transportation in the inner dump is as follows.

$$
F=3.65 \times(18000000 \times 3.4 \times 1.2-150000)=262581000
$$

The reduced height of the inner dump is optimized by the method above, namely reducing the elevation of the inner dump.

$$
\Delta h=\frac{h \Delta L_{p}}{\Delta L_{p}+L_{p}}=\frac{240 \times 42}{42+143}=54
$$

The following figure shows the comparison of the latest inner dump and the original dump on the same profile after optimization. 


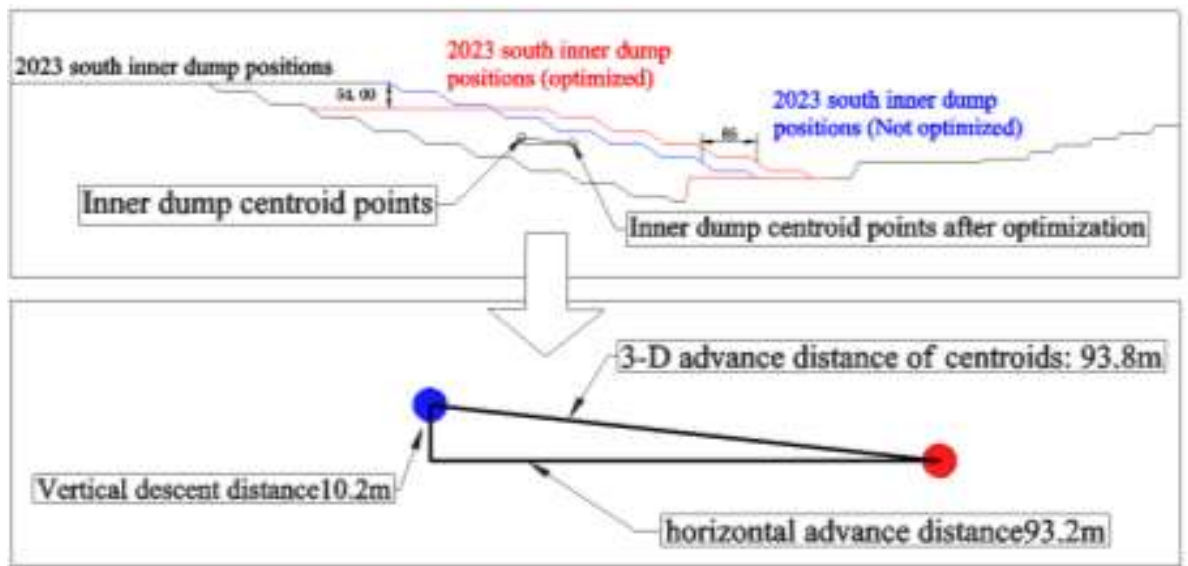

Fig 12 Comparison of effect sections before and after optimization 1

After optimization, the centroid moved $93.2 \mathrm{~m}$ towards the inner dump and also moved downward $10.2 \mathrm{~m}$. In addition, the bench toe of the last step moved $85 \mathrm{~m}$ towards the inner dump, and the tracking distance between the stope and the inner dump is $50 \mathrm{~m}$, which meets the requirements of the safety procedures.

Regarding the inner dump after optimization, the load distance of the inner dump is calculated as $3.58 \mathrm{~km}$, and the cost is as follows.

$$
\mathrm{F}=3.58 *(18000000 * 3.4 * 1.2-1500000)=257545200
$$

It is estimated that the saved cost could reach 5,035,800 yuan.

2. mined until a certain year: In the open-pit mine, the working line length is $2,200 \mathrm{~m}$ and the advance distance is $225 \mathrm{~m}$ in the stope; the working line length of the inner dump is $1,800 \mathrm{~m}$. When the dump space was not optimized, the inner dump needs to be advanced 250 meters away. At this time, the safe distance between the inner dump and the stope is $25 \mathrm{~m}$, which fails to meet the requirements of the specifications. It is a typical stage of the inner dump space insufficiency.

The inner dump was optimized within the same year. The elevation of the dump was increased to $897 \mathrm{~m}$, and it meets the requirements. The computational process is as follows.

$$
\frac{1}{2}[60+(60+2 \operatorname{Vhcot} 16)] \mathrm{Vh}=25 \times 240
$$

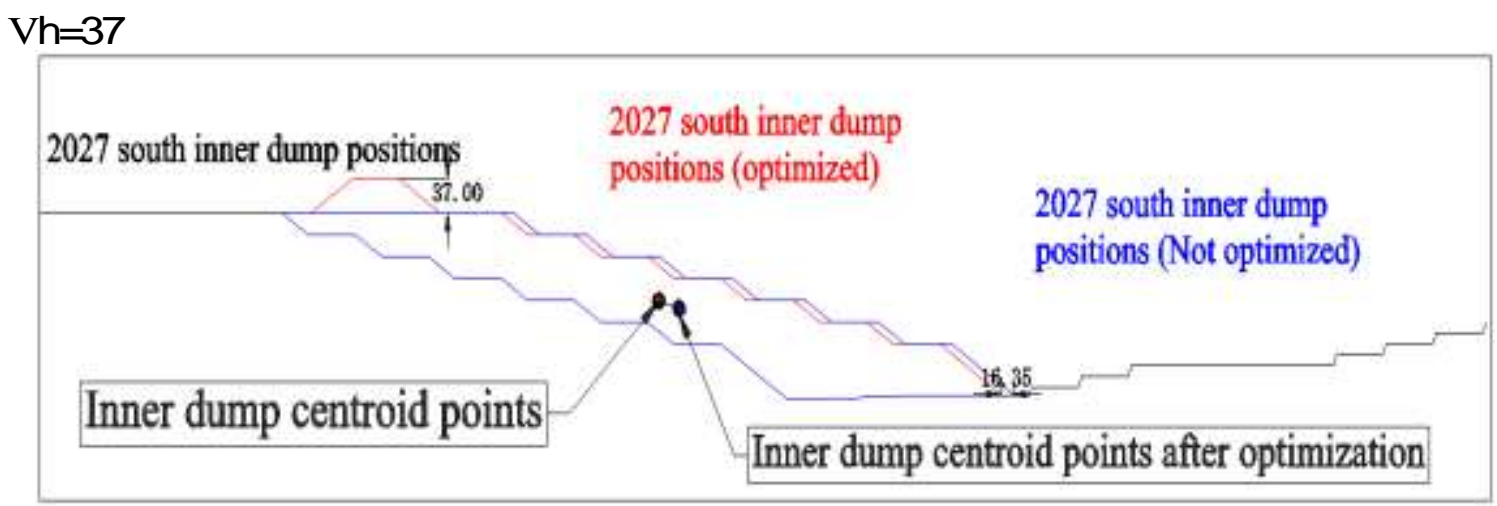

Fig 13 Comparison of effect sections before and after optimization2

\section{Conclusions}

ISSN: 0010-8189 
1. When the stripping project is implemented in the inner dump open-pit mines, the parameters of the inner dump are not constant values and they change along with the changes of the stripping project in order to achieve the maximum economic benefits of open-pit mines.

2. When the space of the inner dump is surplus, reducing the height of the inner dump is better than reducing the working slope angle in terms of saving the load distance so shat the tracking distance between the inner dump and the stope is approximate to a stable value. When the space of the inner dump is insufficient, the way of raising the elevation of the inner dump is preferred. When the inner dump is increased to the limits, the reverse inner dump is done to reduce the area of the land acquisition.

3. The development of the inner dump is dynamically optimized in the two typical stages of the Huolinhe open-pit mine. In this way, the required changes of the inner dump in different stages are obtained. In the stage of the inner dumping surplus, the original inner dumping height reduces by $21 \mathrm{~m}$, and the saved truck transportation cost can reach 5, 035, 800 yuan. In the stage of the inner dumping insufficiency, the land acquisition area of the external dump gets reduced by increasing the height of the dump and using the reverse inner dumping. The combined optimization of the two methods can save more cost than the original plan.

\section{Acknowledgements}

This research was supported by National Natural Science Foundation of China (Grant No. 51974144).

\section{References}

[1] C.S. Zhou, " Stability of dump in open-pit coal mine," Journal of China University of Mining \& Technology, vol. 01, pp. 31-36, 1992.

[2] Y. Bai, "Research on continuation and optimization of Yuanbaoshan open-pit coal mine project," Liaoning Technical University, 2013.

[3] S.L. Chai, R.C. Bai, G.W. Liu, Bo Cao, P. Liu, L. Dai, "Open-pit mine transportation route optimization based on improved genetic algorithm," Chongqing University Journal, vol. 02, pp. 87-95, 2018.

[4] G. Liu, R. Zhang, "Open-pit mine dumping and soil rock flow direction flow optimization model," Chemical Mining Technology, vol. 03, pp. 6-8, 1999.

[5] J.X. Shi, X.R. Liu, S.B. Liao, S.W. Liu, "Analysis of the influence of dumping load on slope stability in mining area," Journal of Mining and Safety Engineering, vol. 28, no. 02, pp. 258-262. 2011.

[6] C. Liu, R.C. Bai, G.W. Liu, B. Cao, "Optimization of coal mining boundary in the lower part of composite coal seam open pit," Journal of China Coal Society, vol. 40, no. 9, pp. 2085-2090, 2015.

[7] L. Zhang, X.H. Ding, Z.Y. Cao, "Research on the optimization of the internal drainage scheme of the end sill in a near-level single coal seam surface mine," Coal Science and Technology, vol. 45, no. 04, pp. 45-49, 2017.

[8] D.F. Gu, W.X. Li, "Computer method and application of open-pit mine dumping planning." Mining and Metallurgical Engineering, no. 02, pp. 18-20, 1996.

[9] R.C. Bai, W.Z. Bai, G.W. Liu, B. Cao, Y.X. Liu, P. Liu, "Optimization of horizontal mining and internal drainage in inclined coal seam narrow and long open-pit mine," Journal of China Coal Society, vol. 42, no. 10, pp. 2601-2608, 2017.

[10] W.J. Guo, "Quick modeling of dump site based on 3D laser scanner. Computer CD Software and Application," vol. 16, no. 21, pp. 80-81, 2013.

[11] R.C. Bai, C. Liu, G.W. Liu, B. Cao, "Optimization of the internal drainage development and transportation system of the seasonally stripped open-pit coal mine," Journal of Chongqing University, vol.37, no. 08, pp. 99-104, 2014.

[12] H.G. Ren, Z.Y. Tan, W.J. Sun, "Optimal design and comprehensive treatment measures for dumping 
sites under complex terrain conditions," Mining and Metallurgy, vol. 25, no.01, pp. 17-21, 2016.

[13] B. Wei, M.C. Fu, Z.K. Bai, W. Fu, "Design of open-pit mine dump based on land saving," Transactions of the Chinese Society of Agricultural Engineering, no. 06, pp. 230-232, 2006.

[14] Y.Y. Liu, J.J. Bao, Y.J. Liu, "Discussion on the safety distance between the bottom of the inner dump and the stope," Open-pit Mining Technology, no. 02, pp. 11-13, 2003.

[15] J.D. Sun, "Research on Dumping Planning of China Coal Pingshuo Antaibao Open-pit Mine," Inner Mongolia University of Science and Technology, 2013. 